\title{
¿A quién esperar en tiempos de globalización? Entre Benedicto XVI y Alasdair MacIntyre
}

\author{
IGNACIO SERRANO DEL POZO \\ Universidad Santo Tomás (Chile) \\ iserrano@santotomas.cl
}

\begin{abstract}
Resumen
El presente trabajo quiere analizar la encíclica Caritas in veritate desde la idea de globalización como clave hermenéutica de todo el documento. Nos parece que este noción -comprendida en sus múltiples dimensiones sociales, éticas, políticas, culturales y espirituales- puede contribuir no sólo a una comprensión más profunda de este texto, sino que también puede ayudar a desentrañar muchas de las críticas que ha recibido esta carta, su excesiva extensión y complejidad temática, así como su silencio sobre el capitalismo y el liberalismo. En una segunda etapa, pretendemos comparar la propuesta de esta encíclica social con el proyecto político de las pequeñas comunidades de Alasdair MacIntyre. La intención es mostrar que lejos de una oposición entre ambas posturas - como de alguna forma lo señaló Jeffrey Nicholas- ellas pueden comprenderse como posturas complementarias, en la medida que realicemos una nueva significación del concepto mismo de globalización, entendida ahora como un proceso dialéctico típicamente postmoderno, siguiendo para ello los análisis de autores como Roland Robertson, Zygmunt Bauman o Ulrich Beck.
\end{abstract}

Palabras claves: Benedicto XVI, MacIntyre, comunidades locales, globalización.

\section{Whom are we waiting for in times of globalization? Between Benedict XVI and Alasdair MacIntyre}

\begin{abstract}
In this paper we seek to analyze the encyclical Caritas in veritate based on the idea of globalization as a bermeneutical key to the whole document. We think that this notion -understood in its multiple social, ethical, political, cultural and spiritual dimensions - can contribute not only to a deeper understanding of this text, but also belp unravel many of the criticisms directed against the letter, its excessive length and thematic complexity, as well as its silence regarding capitalism and liberalism. In a second stage, we set out to compare the proposal of this social encyclical with Alasdair MacIntyre's political project of local communities. Our purpose lies in demonstrating that far from an opposition between the two positions - as Jeffrey Nicholas has in a way pointed out- that they can be understood as complementary, to the extent that we make a new meaning of the very concept of globalization, now understood as a typically postmodern dialectical process based on to the analyses of authors such as Roland Robertson, Zygmunt Bauman or Ulrich Beck.
\end{abstract}

Keywords: Benedict XVI, MacIntyre, local communities, globalization.

Doctor en Filosofía por la Universidad de Navarra y Director del Centro de Estudios Tomistas de la Universidad Santo Tomás, Santiago de Chile. Entre sus publicaciones se encuentra Debilidad de la voluntad y dominio racional: el problema de la incontinencia y la continencia en la filosofía de Tomás de Aquino (2013) y varios artículos especializados sobre la tradición tomista y A. MacIntyre.

Este artículo es resultado del proyecto de investigación Fondecyt 11130034. 


\section{Introducción}

El propósito de este artículo es analizar la encíclica social Caritas in veritate teniendo como clave interpretativa de este documento la noción de globalización ${ }^{1}$. Nos parece que esta idea, si se entiende en sus múltiples dimensiones, puede contribuir a desentrañar las complejidades de la tercera y última encíclica de Benedicto XVI. Fechada el 29 de junio de 2009, este documento se presenta como una relectura de la carta Populorum progressio a más de cuarenta años de su publicación, y en la misma línea del documento de Pablo VI, pretende dar las orientaciones pastorales para el desarrollo integral de la humanidad en una época cuya «novedad principal ha sido el estallido de la interdependencia planetaria, ya comúnmente llamada globalización» $(C V, 33)$.

En una segunda parte de este trabajo, pretendemos comparar la propuesta de esta encíclica social con el proyecto político de las pequeñas comunidades de Alasdair MacIntyre. MacIntyre es un pensador escocés radicado en Estados Unidos, reconocido por su contribución a la rehabilitación de la ética de la virtud aristotélica; pero además, en no menor medida, es conocido como uno de los pensadores más críticos y profundos de la tradición liberal hegemónica de la cultura política actual. De hecho, desde la publicación en 1981 de su clásica obra After Virtue, se fue convirtiendo - sin quererlo- en uno de los pensadores preferidos por el movimiento comunitarista, quienes vieron en esta obra una potente base teórica para el rescate de las instituciones sociales y las identidades comunitarias de cara al individualismo liberal ${ }^{2}$.

Si bien una comparación semejante ha sido acometida por Jeffrey Nicholas en un reciente artículo titulado "Local Communities and Globalization in Caritas in veritate" (Nicholas, 2011), nos parece que su es-

1 Si bien el título de la encíclica (lo mismo que su introducción) pueda hacernos creer que el objetivo de este documento consiste en profundizar en la dimensión moral y política de la caridad, una especie de complemento a Deus caritas est, lo cierto es que no pocos autores han visto más bien en la globalización la idea matriz de todo el documento (Pabst, 2012; Sowle, 2010; Christiansen, 2010). «Globalization is one of the major contemporary trends that Benedict addresses. In doing so, he takes up a characteristically Catholic theme with resonances back to John XXIII's exposition of "universal common good" and Vatican's definition of the church as a sacrament "of the unity of the human family" with the concomitant duty to foster the processes of "socialization" at work in the contemporary» (Christiansen, 2010: 15).

2 Sobre el comunitarismo y su enfrentamiento con el liberalismo, debate fuertemente desarrollada en los años 80 en los Estados Unidos, lo mejor es la obra clásica de Mulhall y Swift (1992). Sobre la conflictiva posición de MacIntyre frente al tema pueden revisarse dos breves publicaciones de éste pensador I'm not communitarism, but..., $\mathrm{y}$ The spectre of communitarianism, citadas en bibliografía de referencia. 
fuerzo tiene intuiciones interesantes pero no analizadas con suficiente profundidad. Por lo demás, y más importante aún, el autor utiliza un concepto demasiado pobre de globalización, que lo obliga a extremar las diferencias entre el Romano Pontífice y el filósofo escocés. Nuestra intención, por el contario, es mostrar que en esta comparación no hay dos polos en disputa; sino que, por el contario, la misma universalidad de la globalización puede contribuir al renacimiento de comunidades locales, en la medida que comprendamos la globalización de modo dialéctico, en tensión creadora con la misma localidad, como han hecho importantes teóricos de este fenómeno como Roland Robertson (2000), Zygmunt Bauman (1999) o Ulrich Beck (1998).

\section{Benedicto XVI y la globalización en sus múltiples dimensiones}

Desde su publicación Caritas in veritate no ha dejado indiferente prácticamente a nadie, ni al mundo público ni al académico. Mientras para algunos autores Benedicto XVI ofrece en esta carta «las más radical enseñanza que un pontífice haya dado sobre economía en tiempos modernos» (Christiansen, 2010: 4), otros le han criticado fuertemente su condescendencia con ciertas ideologías, particularmente con la ideología liberal y el capitalismo. Esto sería particularmente grave en cuanto esta encíclica habría sido retrasada - supuestamente- para poder abordar más reflexivamente la crisis financiera del 2008, causada, entre otros factores, por la desregulación económica propia del sistema económico liberal $^{3}$. Así, Bernardo Pérez Andreo, por ejemplo, llega a sostener que este documento revela un verdadero giro en la enseñanza social de la Iglesia Católica, de aceptación tácita al capitalismo y de legitimación del lucro, lo que no había pasado con Pablo VI o Juan Pablo II, que siempre se habían mostrado críticos frente a concepciones individualistas de la economía (Pérez Andreo, 2010). Bernard Laurent, por su parte, aunque con menos vehemencia, hace notar que Caritas in veritate nunca menciona las palabras liberalismo ni capitalismo, y denuncia que este documento parece centrarse más en la responsabilidad de los individuos que en la denuncia a determinadas escuelas de pensamiento económico (Laurent, $2010)^{4}$.

3 Decimos supuestamente porque no conocemos información oficial que explique el retraso de esta encíclica, aunque su sentido era que apareciera dos años antes, fecha que celebraba el cuadragésimo aniversario de Populorum Progressio (Crepaldi, 2014).

A este respecto, es decidor el párrafo 36: «No se debe olvidar que el mercado no existe en su estado puro, se adapta a las configuraciones culturales que lo concretan y condicionan. [...] Por eso, no se deben hacer reproches al medio o al instrumento sino al hombre, a su conciencia moral y a su responsabilidad personal y social». 
Para sortear muchas de estas críticas, conviene precisamente atender la idea de globalización. Incluso esta noción puede iluminar los aspectos formales de la encíclica, pues nos enfrentamos con un documento denso, demasiado largo, y con una multitud de aristas ${ }^{5}$. Y esta idea es, además, suficientemente potente para explicar el silencio que existiría sobre la ideología liberal.

Aunque suene aventurado, creemos que el liberalismo como tal no aparece en Caritas in veritate pues Benedicto XVI concibe la globalización como la nueva ideología del tiempo presente, corriente que bien puede reemplazar la época de los dos grandes bloques, marxista y capitalista. Para el Papa Ratzinger la globalización no sólo representa un nuevo orden mundial, sino que ella misma puede ser vista como vehículo de la mayor amenaza que se cierne sobre la humanidad en los actuales tiempos; nos referimos al primado de la técnica planetaria como forma dominante de pensamiento. Esta idea que puede recordarnos los análisis heideggerianos sobre la técnica o la crítica de la Escuela de Frankfort a la racionalidad instrumental, ya está presente en Pablo VI como advertencia al surgimiento de la «tecnocracia» tras el agotamiento de las ideologías ${ }^{6}$, y es retomada por Benedicto XVI como una crítica al dominio de la racionalidad técnica omnipresente en los actuales procesos de desarrollo mundial $(C V, 14)$. Ésta es la ideología que le interesa al Pontífice, pues ella significa el primado de la eficiencia y la utilidad como los únicos criterios de acción y de verdad ${ }^{7}$. En esa misma perspectiva, no basta oponerse al liberalismo y el mercado haciendo intervenir al Estado, como

5 Para el mismo Christiansen el problema no sólo es su prosa complicada, sino que esta encíclica retomaría una exposición demasiado deductiva, la via doctrinae preconciliar por sobre la via inventionis de carácter inductivo de Pablo VI (Christiansen, 2010: 10).

$6 \quad$ Octogesima adveniens, 29: «Si hoy día se ha podido hablar de un retroceso de las ideologías, esto puede constituir un momento favorable para la apertura a la trascendencia y solidez del cristianismo. Puede ser también un deslizamiento más acentuado hacia un nuevo positivismo: la técnica universalizada como forma dominante del dinamismo humano, como modo invasor de existir, como lenguaje mismo, sin que la cuestión de su sentido se plantee realmente». Populorum progressio, 34: «La tecnocracia del mañana puede engendrar males no menos temibles que los del liberalismo de ayer. Economía y técnica no tienen sentido si no es por el hombre, a quien deben servir. El hombre no es verdaderamente hombre, más que en la medida en que, dueño de sus acciones y juez de su valor, se hace él mismo autor de su progreso, según la naturaleza que le ha sido dada por su Creador y de la cual asume libremente las posibilidades y las exigencias».

$7 \quad$ Caritas in veritate, 70 : «El proceso de globalización podría sustituir las ideologías por la técnica, transformándose ella misma en un poder ideológico, que expondría a la humanidad al riesgo de encontrarse encerrada dentro de un a priori del cual no podría salir para encontrar el ser y la verdad». Caritas in veritate, 74: «Pero la racionalidad del quehacer técnico centrada sólo en sí misma se revela como irracional, porque comporta un rechaza firme del sentido y del valor». 
hizo en su momento León XIII con Rerum novarum, pues esta vía es insuficiente bajo los actuales procesos de globalización y de apertura de los mercados $(C V, 39)$.

Con todo, no conviene sacar conclusiones apresuradas, ni creer que por esta razones la globalización es el enemigo de esta carta. La complejidad y riqueza de este documento radica precisamente en que la globalización, en palabras de Benedicto XVI (citando a Juan Pablo II), «no es a priori, ni buena ni mala. Será lo que la gente haga de ella» $(C V, 42)$. Nos corresponde entender, entonces, «qué hace» el sucesor de Pedro con el fenómeno de la globalización.

Lo primero que importa señalar es que entenderíamos mal la carta de Benedicto XVI si supusiésemos que la preocupación del Pontífice en esta encíclica es el fenómeno de la globalización como un acontecimiento socioeconómico propio de la edad contemporánea. Aunque pueda sonar paradójico, los documentos sociales de la Iglesia, lo mismo que este texto, siempre han pretendido distanciarse de aspectos técnicos o de política contingente. En este sentido, la mirada de esta carta está puesta en el proceso invisible que late al interior de la globalización. Pues detrás de este proceso se esconde precisamente una integración planetaria de la humanidad, entendida en este contexto como la gran familia humana ${ }^{8}$. En esa línea, conviene comprender los diversos y múltiples niveles en que se mueve esta idea de globalización.

En un primer nivel, quizás el más simple, podemos decir que la noción de globalización puede considerarse como el foco que ilumina una serie de temas específicos, pero extremadamente prácticos, que son abordados en este documento. Se trata de aquellas cuestiones más marcadamente sociales. En primer lugar, la globalización pone de manifiesto las reales dimensiones de los actuales conflictos económicos y la escala en la que se «relacionan» ricos y pobres, ahora como encuentro o desencuentro entre países industrializados y países en vía de desarrollo, o entre países ricos y naciones agrarias. El pontífice se lamenta de que aún continúe existiendo «el escándalo de las disparidades hirientes» entre países denunciado por Pablo VI, y critica la ineficiencia de mucha de la ayuda internacional emprendida, corrompida tanto por culpa de donantes como de beneficiarios $(C V, 22)$. A este respecto, hace un llamado concreto a evitar formas exageradas de protección de propiedad intelectual por

8 Caritas in veritate, 42: «La verdad de la globalización como proceso y su criterio ético fundamental vienen dados por la unidad de la familia humana y su crecimiento en el bien. Por tanto, hay que esforzarse incesantemente para favorecer una orientación cultural personalista y comunitaria, abierta a la trascendencia, del proceso de integración planetaria». 
parte de los países ricos, lo que sería especialmente grave en materia sanitaria, causante de muchas de estas injusticias de carácter global $(C V, 22)$. Otra situación que puede enmarcarse dentro de la problemática de la globalización es la preocupación que evidencia Benedicto XVI porque en un mercado mundial y sin fronteras se reduzcan las redes de seguridades sociales y las organizaciones sindicales pierdan influencia $(C V, 25)$. A propósito de esto mismo, Benedicto recordará el llamado de su predecesor a «una coalición mundial a favor del trabajo decente» $(C V, 63)$. Otro tema que también puede leerse desde esta idea de globalización e interdependencia es la cuestión de la ecología y la alianza entre ser humano y medio ambiente. El Pontífice piensa aquí en una responsabilidad global por custodiar, cultivar y hacer productivo los recursos naturales, considerando el inmenso deber que las actuales generaciones tienen con las nuevas. Pero además, se puede comprender aquí la misma solidaridad que le cabe a los países industrializados con el planeta entero y su deber de disminuir el gasto energético y de redistribuir los recursos ${ }^{9}$. Un tercer tema que puede ser mirado en la misma óptica, es el de los fenómenos del turismo internacional y de las migraciones. Sobre el primero, Benedicto XVI mira con preocupación que el turismo pierda su significado cultural y educativo para degradarse en un turismo consumista y hedonista, y en el peor de los casos, en turismo sexual $(C V, 61)$. Sobre las migraciones, el actual Papa emérito hace un llamado a enfrentar este problema desde adecuadas normativas internacionales, las que armonicen las exigencias y derechos de los países de destino y las familias y trabajadores que emigran, pues no es posible atender esta realidades como países individuales o aislados $(C V, 62)$.

A estas primeras consideraciones sobre la globalización e interdependencia se añaden otras incluso de mayor importancia. Como lo señalamos en párrafos atrás, no hay que perder de vista que Caritas in veritate aparece por el explícito deseo de Benedicto XVI de rendir un homenaje y recordar a Pablo VI, particularmente al mensaje de su encíclica social Populorum progresio sobre una humanidad en vías de unificación. Es cierto que el fenómeno de la dependencia planetaria ya había aparecido en el capítulo II de la Constitución Gaudiem et spes dedicada a la comunidad humana y a la promoción del bien común ${ }^{10}$, lo mismo que en Mater et

9 Caritas in veritate, 50: «En nuestra tierra hay lugar para todos: en ella toda la familia humana debe encontrar los recursos necesarios para vivir dignamente con la ayuda de la naturaleza misma, don de Dios a sus hijos».

10 Gaudium et spes, 23, 24, 25: «Entre los principales aspectos del mundo actual, se cuenta la multiplicación de las relaciones mutuas entre los hombres, a cuyo desarrollo contribuyen mucho los modernos progresos técnicos. [...] Dios, que cuida paternalmente de todos, ha querido que todos los hombres formen una única familia y 
magistra cuando Juan XXIII hace un llamado a la colaboración en el plano mundial ${ }^{11}$; sin embargo, para el autor de Caritas in veritate, es el Papa Montini el pontífice que capta la relación que existiría entre el fenómeno político-social y el ideal ético-espiritual que encierra: «Pablo VI entendió claramente que la cuestión social se había hecho mundial y captó la relación recíproca entre el impulso hacia la unificación de la humanidad y el ideal cristiano de una única familia de los pueblos, solidaria en la común hermandad» $(C V, 13)$. En otras palabras, lo que está en el meollo de este mensaje es la constatación de que estamos en un época verdaderamente planetaria, en la que la humanidad avanza hacia la unificación y la sociedad se mueve hacia la globalización, por lo que todo esfuerzo social necesariamente debe considerar esta oportunidad de que el mundo entero se constituya como verdadera comunidad de naciones $(C V, 7)$. A esta ocasión conmemorativa se une además la situación económica internacional que rodea la publicación de esta encíclica, que pone más de manifiesto aún la relevancia de la globalización. Pues si bien Benedicto XVI no ahonda en las causas ni en los efectos de esta crisis que llama actual, no duda de que ella ha adquirido dimensiones globales, con fenómenos económicos y políticos cada vez más interrelacionados y con implicaciones recíprocas $(C V, 21)$.

Además de todo lo dicho, no debe olvidarse que Benedicto XVI escribe esta encíclica no sólo como pastor, preocupado de la situación económica vigente y del desarrollo integral de la humanidad, sino además como un teólogo y filósofo, por lo que las razones de fondo para hacer pivotar toda su encíclica social en la globalización son metafísicas. Es difícil menospreciar la importancia de estas bases, pues sus raíces son justamente, como ha señalado Ruszala (2010), las que permiten discernir

se trate entre sí con espíritu fraterno. [...] De la interdependencia cada vez más estrecha y extendida paulatinamente a todo el mundo se sigue que el bien común [...] se hace cada vez más universal y por ello implica deberes y derechos que se refieren a todo el género humano».

11 Mater et magistra, 200, 202: «Las relaciones entre los distintos países, por virtud de los adelantos científicos y técnicos, en todos los aspectos de la convivencia humana, se han estrechado mucho más en estos últimos años. Por ello, necesariamente la interdependencia de los pueblos se hace cada vez mayor. [....] Sucede por esto que los Estados aislados, aun cuando descuellen por su cultura y civilización, el número e inteligencia de sus ciudadanos, el progreso de sus sistemas económicos, la abundancia de recursos y la extensión territorial, no pueden, sin embargo, separados de los demás resolver por sí mismos de manera adecuada sus problemas fundamentales. Por consiguiente, las naciones, al hallarse necesitadas, de unas de ayudas complementarias y las otras de ulteriores perfeccionamientos, sólo podrán atender a su propia utilidad mirando simultáneamente al provecho de los demás. Por lo cual es de todo punto preciso que los Estados se entiendan bien y se presten ayuda mutua». 
lo positivo y lo negativo de un proceso considerado neutral para Benedicto XVI. Para el Santo Padre, la unidad de la comunidad de los pueblos y las naciones es una «anticipación que prefigura la ciudad de Dios sin barreras» $(C V, 7)$. En esto se revela la influencia agustiniana del Pontífi$\mathrm{ce}^{12}$, y básicamente por dos motivos. En primer lugar, porque presupone una visión metafísica en un sentido amplio, como ontología y teología, inspirada en la razón y la revelación. No es posible comprender los alcances de la globalización para quien sólo la mira en términos económicos o sociológicos, ni siquiera lo es para quien analiza este fenómeno desde la filosofía, pues para una correcta comprensión de la globalización se requiere, como la misma carta lo señala, «ampliar nuestro concepto de razón y de su uso» $(C V, 31)$. Esto significa un problema para quienes no miran desde la fe; pero para Ratzinger, sin esta mirada, parece no haber posibilidad de una visión verdaderamente holística que abarque todos los aspectos de un fenómeno: económicos, sociales, culturales y espirituales. En segundo lugar, San Agustín se hace presente de otro modo en el pensamiento del Pontífice. El sucesor de Pedro parece abordar la globalización - mutatis mutandi- de forma análoga a lo realizado por San Agustín con la noción de civitas. Así como Roma es la ciudad concreta con la que se encontró el Obispo de Hipona, y con esta noción comprende alegóricamente a la Iglesia, del mismo modo Benedicto XVI parece emprender una tarea «des-sociologizante» y «des-economicista» de la globalización, que sin negar su sentido empírico primero, la «des-literaliza» para comprenderla en un sentido «figurado» ${ }^{13}$. En esa línea de reflexión, la globalización no es simplemente una situación real que sucede actualmente, como tampoco es un ideal ético que podría realizarse con el empeño de todos, sino que es más bien la prefiguración de la gran familia humana. Sólo una perspectiva metafísica permite superar la globalización como categoría político-económica, aunque ésta nunca quede anulada del todo. Esta «globalización mística» a falta de otro mejor término, se construye desde el amor en la verdad y la fraternidad, pero no por ello pierde su momento fáctico de lugar de interdependencia planetaria de todos los hombres.

Pérez Andreo ha señalado algo semejante a lo que venimos diciendo. La encíclica Caritas in veritate se ubica en el mismo horizonte de crisis que

12 «Benedict's visions of the "universal city of God", which is the goal of the history of the human family, seems to be a modification of the Augustinian conception of the city of God that coexists in time with the city of man, distinguished by the object of their loves» (Christiansen, 2010: 7).

13 Importa decir que este modo de comprender el concepto de Civitas Dei, que avanza de la «literalidad» a la alegoría, es utilizado por Ratzinger en su tesis doctoral. Una síntesis de este trabajo puede verse en Ratzinger (2014). 
le tocó vivir al Obispo de Hipona: los finales del Imperio Global Posmoderno son semejantes en muchos aspectos a la caída del Imperio Romano y, como ha señalado el profesor de la universidad de Murcia:

Civitate Dei es la respuesta de Agustín a los interrogantes de los tiempos, Dios ha querido la caída del Imperio Romano cristiano como camino para la construcción de un mundo cristiano más amplio. De la misma manera hoy, nos propone la encíclica, Dios quiere la quiebra del mundo global como medio para alcanzar una familia cristiana universal, una nueva Ciudad de Dios donde el cristianismo juegue el papel de garante de la moral y la ley natural (Pérez Andreo, 2010: 44-45).

Es discutible que Benedicto XVI esté profetizando la caída de la globalización, pero sí coincidimos en que esta carta se construye en el horizonte de una nueva época global postmoderna.

Sobre la base de lo dicho, es claro además por qué para el autor de Caritas in veritate «oponerse a la globalización sería una actitud errónea, preconcebida, que acabaría por ignorar un proceso que tiene también aspectos positivos con el riesgo de perder una gran ocasión para aprovechar las múltiples oportunidades de desarrollo que ofrece» $(C V, 42)$. Benedicto hace un llamado así a aceptar estos desafíos de manera confiada, más que de forma resignada o de modo fatalista $(C V, 21)$. Este aprovechar la globalización consiste, en definitiva, en valorarla como expresión y camino de unidad, y orientarla precisamente hacia una humanidad más solidaria, atendiendo sus dimensiones culturales, éticas, metafísicas y teológicas $(C V, 42)$. Es cierto que - como señala el Santo Padre- hay mucho que discernir, «costras que limpiar y sombras que despejan», y que la misma globalización - como dijimos- puede presentarse como un poder ideológico de dominio técnico sobre la persona y las comunidades, que acreciente en lugar de disminuir la pobreza material y espiritual. Sin embargo, en todo el documento prevalece la confianza cristiana en que esta globalización, interrelación e interdependencia, vista en sus múltiples dimensiones, e insuflada por la caridad en la verdad, es capaz de anticipar la ciudad de Dios en la Tierra. «La acción del hombre sobre la tierra, cuando está inspirada y sustentada por la caridad, contribuye a la edificación de la ciudad de Dios universal hacia la cual avanza la historia de la familia humana» $(C V, 7)$.

No conviene cerrar esta reflexión sin atender un aspecto que aparece en la carta, relacionado con la misma globalización, y que nos parece el más controvertido de toda la encíclica, y por ello muy interesante. En el contexto descrito, Benedicto XVI hace mención a la necesidad de una autoridad planetaria que conduzca a la humanidad al bien común. Este es 
un tema que había aparecido con Juan XXIII, pues en Pacem in terris había hablado justamente de que la situación del momento demandaba una autoridad política de competencia mundial, especial para tiempos en que el mismo bien común tiene carácter planetario ${ }^{14}$. El problema, como lo vio también san Juan XXIII, y lo alerta Benedicto XVI, es que esta instancia tiene tantas ventajas como riesgos. Probablemente el riesgo más evidente es la cercanía de este ideal de autoridad con el gobierno actual que conduce la $\mathrm{ONU}$, particularmente porque como el mismo Benedicto reconoce, la Organización de las Naciones Unidas en su actual estructura carece de la imparcialidad y solidaridad requerida para una autoridad política mundial, dado que en ella gobiernan los fuertes en desmedro de los más débiles $(C V, 67)$. El segundo riesgo de esta noción es que ella, si no quiere permanecer como mera autoridad moral, debe disponer de poder efectivo, pero con ello se ve comprometida y debilitada la autonomía de acción de los cuerpos intermedios. Esto también es reconocido por el autor de la encíclica, de ahí que insista en la necesidad de recordar el principio de subsidiaridad y la división de poderes como remedio a este problema $(C V, 57)$. No obstante estas dificultades, y siguiendo la analogía de los párrafos precedentes, pareciera ser que la misma familia humana requiriese un pater familias ${ }^{15}$ humano que sea capaz de garantizar el desarrollo de todos y la cooperación de las partes, dando así concreción real al concepto de familia de naciones $(C V, 67)$.

\section{Las pequeñas comunidades locales en MacIntyre}

Resulta ilustrativo comparar el enfoque de Benedicto XVI con la postura filosófica de Alasdair MacIntyre. MacIntyre se caracteriza por ser un agudo crítico de la modernidad. Marxista primero, aristotélico después, tomista (convertido) en sus últimos años, considera que la modernidad ha fracaso en su proyecto ilustrado de alcanzar un ideal común y consensos de racionalidad y objetividad en el ámbito de la moral y la política. Para este pensador existen consensos retóricos, o simulados, que denotan las incoherencias de una modernidad liberal hecha de muchas tradiciones, muchas veces incompatibles unas con otras. Lo que tenemos en realidad hoy es una sociedad compartimentalizada en una serie de

14 Pacem in terris 137: «como hoy el bien común de todos los pueblos plantea problemas que afectan a todas las naciones, y como semejantes problemas solamente puede afrontarlos una autoridad pública cuyo poder, estructura y medios sean suficientemente amplios y cuyo radio de acción tenga un alcance mundial, resulta, en consecuencia, que, por imposición del mismo orden moral, es preciso constituir una autoridad pública general».

15 La analogía aparece en Sowle (2010: 306). 
intereses y proyectos que denotan más bien emotivismo e individualismo como notas distintivas (MacIntyre, 1984; MacMylor, 1994; Pinkard, 2003).

Ahora bien, ello no sólo constituye una crítica, sino que hay en MacIntyre una declaración explícita de la necesidad de superar esta mezcla mal armada de visiones propia del liberalismo, mediante su reemplazo por una tradición verdaderamente robusta, la aristotélico-tomista ${ }^{16}$. Sólo en ella es posible recuperar la práctica de las virtudes que posibilitan el desarrollo del hombre y la comunidad.

Consecuente con su invectiva a la modernidad liberal, MacIntyre es, además, un agudo crítico de las ideas de estado y nación, y un férreo defensor de las pequeñas comunidades locales como el espacio que permite alcanzar el bien común y desarrollar la tradición aristotélica de virtudes. Así cierra su más famoso libro After Virtue: «Lo que importa ahora es la construcción de formas locales de comunidad, dentro de las cuales la civilidad, la vida moral y la vida intelectual puedan sostenerse a través de las nuevas edades oscuras que caen sobre nosotros» (MacIntyre, 1984: 322). Mientras Benedicto XVI pretende aprovechar la globalización como una oportunidad, MacIntyre da cuenta de la aguda fragmentación que afecta a las sociedades modernas, cuya marcada heterogeneidad de valores y diversidad de intereses impiden a sus miembros compartir una noción común de bien a gran escala. Sólo es posible, en ese escenario, pensar en una idea de bien común para pequeñas comunidades, mayores que la familia y menores que el Estado: escuelas, parroquias, universidades, clubes deportivos, asociaciones profesionales, y agrupaciones de ese estilo (MacIntyre, 1999a; Knight, 1999). Sólo estas sociedades pequeñas, e idealmente autosuficientes, posibilitan mantenerse inmunes a los poderes impersonales y burocráticos del Estado, y a las fuerzas económicas del mercado ${ }^{17}$. No es que MacIntyre idealice a la comunidad en sí, él es consciente de que estas pequeñas comunidades pueden también ser caldo de cultivo para ciertos vicios: la complacencia y el prejuicio, por ejemplo, el rechazo arbitrario a los extraños, incluso el mismo culto a la comunidad (MacIntyre, 1999b: 142). Sin embargo, la pequeña comunidad posibilita dos características que resultan fundamentales para el desarrollo del bien común: la primera es la deliberación racional sobre lo que se quiere, realizada por medio de la conversación y discusión; la segunda

16 La superioridad del tomismo aparece en una obra posterior a After Virtue, en Three Rival Versions of Moral Enquiry, y será desarrollada en trabajos posteriores.

17 «Such societies must be small-scale and, so far as possible, as self sufficient as they need to be protect themselves from destructive incursions of the state and the wider market economy» (MacIntyre, 1999b: 248). 
es el desarrollo de «prácticas» en un sentido bien preciso, de actividades en las que sus integrantes desarrollan bienes de excelencia y aprenden las reglas no de un modo teórico o meramente reflexivo. En el contexto de nuestro tema, importa decir que sólo en estas comunidades es posible recrear la virtud de la solidaridad y generosidad, particularmente hacia aquéllos más dependientes y necesitados: niños, viejos y discapacitados. El Estado o la nación, lo mismo que el mercado, participan de otra lógica, que no está centrada en la gratuidad y dependencia («social relationship uncalculted of giving and receiving»), sino más bien en la lógica de la utilidad y la eficiencia. Este es el sentido del porqué MacIntyre ha preferido distanciarse del comunitarismo y republicanismo norteamericano, por considerar que ambas tendencias intentan vanamente superar el individualismo liberal por medio de una concepción fuerte del estado-nación como último garante de un supuesto bien común general ${ }^{18}$.

Para Alasdair MacIntyre estas comunidades locales requieren una tercera característica en vista de alcanzar su bien común: reconocer la obediencia a ciertas reglas comunes conocidas por todos. Entre una lista de virtudes podemos pensar en la veracidad, el respeto a los otros, la confianza en el cumplimiento de las promesas. Pero más allá de este listado, importa destacar la relación que existiría entre estas virtudes con los principios contenidos en la ley natural de Santo Tomás. Dejo aquí planteado el punto si es o no efectivamente tomista esta concepción, ya que existe una discusión interesante en el mundo anglosajón al respecto (Coleman, 1994; Hibbs, 2004; Osborne, 2008). Dadas las orientaciones de este trabajo, conviene concentrarse solamente en los argumentos del mismo MacIntyre para apelar a Santo Tomás. Para MacIntyre, la ley natural se constituye como la única regla que puede ser compartida por todos los que pertenecen a la comunidad, sin extrañamientos frente a su poder coercitivo, pues su fuerza es la fuerza de lo «habitual», no del arbitrio de un poder distante. Las entidades como el estado y la nación, lo mismo que el mercado, son extrañas a la naturalidad de este tipo de reglas, pues justamente ellas se constituyen desde parámetros diferentes: marcadas por la burocratización y profesionalización de sus distintas instancias, o bien por intereses económicos y fuerzas mercantiles. Eso es lo que hace subversiva a la ley natural (MacIntyre, 2006). Esa es la razón, además, por qué para MacIntyre Tomás de Aquino no considera que la autoridad central debe incursionar en todos los niveles, pues basta que la ley sancione sólo los más graves vicios, aquéllos que son conocidos por

18 Para MacIntyre el Estado es simplemente «un conjunto de convenios institucionales para imponer la unidad burocrática a una sociedad que carece de consenso moral auténtico» (MacIntyre, 1984: 312). 
la mayoría y que atentan realmente contra el bien de la comunidad: homicidio, robo y cosas semejantes. El filósofo escocés cita para su defensa la Suma Teológica I-II, cuestión 96 a. $2^{19}$. Para lo demás basta el poder de la costumbre, que sólo debe ser alterado por razones muy fuertes. «La costumbre tiene fuerza de ley y contribuye a su observancia», es la frase que MacIntyre utiliza de Santo Tomás, cuya referencia es la cuestión 97, a. $2^{20}$.

\section{Posible encuentro entre Benedicto XVI y MacIntyre}

La última parte de este trabajo pretende comparar ambas propuestas, intentando descubrir la relación que podría existir entre globalización y comunidades locales. En principio, parecería ser que estamos en dos posturas que se encuentran en sus antípodas, pues mientras uno apela a la globalización y la universalidad, el otro intenta romper las lógicas de poder de la sociedad moderna desde la particularidad y las pequeñas comunidades. Este mismo juicio podría verse reforzado si atendemos a la matriz conceptual en la que se inserta cada uno de estos pensadores. Mientras Benedicto XVI parece inspirarse en la idea agustiniana de la ciudad de Dios, MacIntyre apela a la tradición aristotélico-tomista para defender su política de las pequeñas comunidades locales semejante a las polis griegas ${ }^{21}$.

Una línea semejante utiliza Jeffrey Nicholas en un trabajo dedicado a ambos autores, pues si bien entiende que ambas propuestas están en la misma línea de crítica a las injusticias de la sociedad, ha notado, por ejemplo, que la pretensión de la encíclica de volvernos protagonistas de

19 Suma teológica I-II, q.96 a.2 co.: «La ley humana está hecha para la masa, en la que la mayor parte son hombres imperfectos en la virtud. Y por eso la ley no prohíbe todos aquellos vicios de los que se abstienen los virtuosos, sino sólo los más graves, aquellos de los que puede abstenerse la mayoría y que, sobre todo, hacen daño a los demás, sin cuya prohibición la sociedad humana no podría subsistir, tales como el homicidio, el robo y cosas semejantes».

20 Suma teológica $\mathrm{I}-\mathrm{II}$, q.97 a.2 co.: «El cambio de las leyes comporta ciertos riesgos para el bien común. Porque la costumbre ayuda mucho a la observancia de la ley, tanto que lo que se hace en contra de la costumbre ordinaria, aunque sea más llevadero, parece más pesado. Por eso, cuando se cambia una ley se merma su poder de coacción al quitarle el soporte de la costumbre».

21 Decimos semejante, pues el mismo MacIntyre conoce las deficiencias de este tipo de instituciones y no pretende recrearlas de modo anacrónico. Para una discusión sobre esta comparación de pequeñas comunidades y polis griega, véase el juicio de Beiner (2000: 463): «MacIntyre may be of the view that ancient forms of moral and political life furnish a critical standard for judging the dificiencies of contemporary ethical life, but nothing in his work suggest that he welcomes project of re-creating the polis». De hecho, hay autores que han visto más el ideal de la comunidad benedictina en estas pequeñas comunidades que la ciudad aristotélica (Jones, 1987). 
la globalización más que sus víctimas ${ }^{22}$, sólo es posible desde comunidades locales, pero no a escala global; y, en ese sentido, piensa el articulista, «MacIntyre hace las más significativa corrección a Caritas in veritate». Pues la globalización es para Nicholas, a semejanza de los estados nacionales, y con mayor razón que éstos, un espacio poco propicio para la deliberación y la acción. Un juicio que también compartiría el mismo MacInty$\mathrm{re}^{23}$.

Ahora bien, si se considera más detenidamente el asunto, uno puede darse cuenta de que la tesis comentada yerra en dos suposiciones. La primera es creer que la globalización y la localidad se contraponen como lo universal y lo particular, donde una significa la supresión o la absorción necesaria de la otra. La segunda radica en pensar la globalización como un nivel superior de supra estatalidad, una especie de gobernanza mundial más burocrática y más controladora aún que los estados territoriales. La pregunta es si éste es el único modo de comprender la globalización, y si es éste el modo como la entiende Benedicto XVI. En lo que sigue trataremos de ahondar justamente en estas ideas, con el fin de mostrar que bien pueden coexistir ambas tesis de globalización y localidad, las de Benedicto XVI y de MacIntyre, no como doctrinas opuestas ni como correctora una de la otra, como lo percibe el citado Nicholas, sino más bien como dos focos de una misma realidad.

Para este último propósito es ilustrativo revisar los trabajos de Roland Robertson sobre globalización y localidad. De acuerdo a este autor, quien acuñó el neologismo glocalización para explicar su punto de vista, es un equívoco pensar las tendencias globalizantes como enfrentadas a las manifestaciones más locales, pues, por el contrario, «la globalización ha implicado la reconstrucción, y en cierto sentido la producción, de "hogar", "comunidad", "localidad"» (Roberston, 2000). Para demostrar esta tesis acude a algunos ejemplos, como el movimiento internacional de Youth Hostel de retorno a los valores comunitarios, los intentos globales de defensa de los pueblos nativos, o bien los esfuerzos de la Organización Mundial de la Salud de promover la «salud mundial» mediante la reactivación de la medicina local «indígena». Así también, puede citarse el ejemplo bien conocido en el ámbito del marketing de las técnicas de las compañías globales de adaptarse a los mercados locales e intereses parti-

22 Caritas in veritate, 42: «Debemos ser sus protagonistas [de la globalización], no las víctimas, procediendo razonablemente, guiados por la caridad y la verdad».

23 «I think MacIntyre can make the most significant correction to Caritas in veritate on this point. Lying at the center of MacIntyre's embrace of local communities and his rejection of nation-states and globalization is rational debate and deliberation. Rational debate and deliberation remain absent from nation-states, despite the fact of voting, and nothing suggest anything will be different on the global level» (Nicholas, 2011: 10). 
culares. Pero más allá de estos ejemplos empíricos, lo que ellos ilustran es que la globalización se comprende mal si sólo se entiende como una fuerza unidimensional de homogenización de lo particular, pues, en realidad, mucho de lo local es constituido justamente en referencia de lo global. En ese sentido, la globalización no obedecería sólo a un proceso de superación de pequeñas escalas entendido de manera lineal, ya sea en su vertiente de amplitud del Estado en una suerte de súper imperio planetario, ya sea como dominio de un único mercado mundial; sino más bien respondería a un proceso de reformulación y repotenciación de pequeñas comunidades interpeladas por un mundo global de fondo.

En una línea parecida, Ulrich Beck ha reaccionado críticamente a la tesis de la «macdonaldización del mundo» como un proceso sin contrapeso o inevitable, mostrando que incluso las grandes empresas (Coca Cola y Sony) plantean sus estrategias en términos de «localización global» (Beck, 1998: 76). Si pensamos a nivel político, conviene no perder de vista que la globalización lejos de potenciar la noción de Estado, significa - como ha visto el sociólogo alemán- su resquebrajamiento hacia formas de vida que superan los límites territoriales o nacionales. Es cierto que para este autor la disolución de los estados nacionales debe dar paso a estados trasnacionales autointegrados, pero lo que es un hecho es que la globalización más bien ha empezado a socavar la soberanía del Estado en materia de control, proporcionando en esta misma dinámica descentralizadora mayor influjo a los contextos locales. Ese es el sentido de decir que «la globalización fragmentariza» (Beck, 1998: 81). Algo semejante había señalado Zigmunt Bauman, quien en un estilo más exagerado y retórico, escribió: «En su significado más profundo, la idea [de globalización] expresa el carácter indeterminado, ingobernable y autopropulsado de los asuntos mundiales; la ausencia de un centro, una oficina de control, un directorio, una gerencia general» (Bauman, 1999: 80). Y en este nuevo «desorden mundial» que aparece con la misma globalización de forma causal, «las iniciativas y las acciones destinadas a poner orden son locales y están orientadas a resolver problemas, pero no hay una localidad tan soberbia como para hablar en nombre de la humanidad en su conjunto» (Bauman, 1999: 80). Es más, según estos mismos planteamientos, mientras el Estado significa el triunfo de la ideología moderna de autosuficiencia; la globalidad representaría la postmodernidad o la segunda modernidad centrada en la colaboración.

Dicho esto podemos volver a Caritas in veritate, pues el Pontífice es consciente de este cambio de eje que implica la globalización. Si bien cree apresurado hablar de una desaparición del Estado $(C V, 41)$, él sabe que en este nuevo orden de cosas se ha modificado el poder político 
estatal y se ha limitado su soberanía ${ }^{24}$. Esta situación de globalidad y de retroceso del Estado es justamente propicia además para repensar una gobernanza realizada desde múltiples niveles y en planos diversos. En verdad no hay todavía en Benedicto XVI referencias concretas que puedan explicar la relación dialéctica que habría entre globalización y sociedad civil, entre globalización y comunidades locales, pero eso es más bien porque sigue presente el viejo esquema de rol subsidiario para referirse a los organismos intermedios; pero no en razón de que la globalización no pueda convertirse también en una oportunidad para el desarrollo de contextos locales. Esto, como hemos dicho, es claro cuando se refiere a la posibilidad de una autoridad mundial ${ }^{25}$, pero también existen pasajes que nos recuerdan la crítica a MacIntyre a la lógica del Estado y a la lógica del mercado y la necesidad de reavivar las prácticas locales: «El binomio exclusivo mercado-Estado corroe la sociabilidad, mientras que las formas de economía solidaria, que encuentra su mejor terreno en la sociedad civil aunque no se reducen a ella, crean sociabilidad» $(C V, 39)$, afirma Benedicto XVI, en sintonía con el pensamiento del filósofo escocés.

No deja de ser tremendamente interesante $-\mathrm{y}$ poco advertido- que MacIntyre escribiera en su famoso libro After Virtue de 1981, inmediatamente después de haber hecho referencia a las necesidades de las pequeñas comunidades locales, que para restituir la tradición de las virtudes sólo queda esperar a un nuevo San Benito que detenga a los bárbaros que están aguardando desde dentro. Ahora podemos decir que esta de-

24 Caritas in veritate, 24: «En nuestra época, el Estado se encuentra con el deber de afrontar las limitaciones que pone a su soberanía el nuevo contexto económicocomercial y financiero internacional, caracterizado también por una creciente movilidad de los capitales financieros y los medios de producción materiales e inmateriales. Este nuevo contexto ha modificado el poder político de los estados».

25 Caritas in veritate, 57: «Sin duda, el principio de subsidiaridad, expresión de la inalienable libertad, es una manifestación particular de la caridad y criterio guía para la colaboración fraterna de creyentes y no creyentes. La subsidiaridad es ante todo una ayuda a la persona, a través de la autonomía de los cuerpos intermedios. Dicha ayuda se ofrece cuando la persona y los sujetos sociales no son capaces de valerse por sí mismos, implicando siempre una finalidad emancipadora, porque favorece la libertad y la participación a la hora de asumir responsabilidades. La subsidiaridad respeta la dignidad de la persona, en la que ve un sujeto siempre capaz de dar algo a los otros. La subsidiaridad, al reconocer que la reciprocidad forma parte de la constitución íntima del ser humano, es el antídoto más eficaz contra cualquier forma de asistencialismo paternalista. Ella puede dar razón tanto de la múltiple articulación de los niveles y, por ello, de la pluralidad de los sujetos, como de su coordinación. Por tanto, es un principio particularmente adecuado para gobernar la globalización y orientarla hacia un verdadero desarrollo bumano. Para no abrir la puerta a un peligroso poder universal de tipo monocrático, el gobierno de la globalización debe ser de tipo subsidiario, articulado en múltiples niveles y planos diversos, que colaboren recíprocamente». 
siderata encerraba, sin saberlo, todo un tono profético (MacIntyre, 1984: 322 ).

\section{REFERENCIAS}

-Bauman, Z. (1999). La globalización: Consecuencias bumanas. Buenos Aires: Fondo de Cultura Económica.

-Beck, U. (1998). ¿Qué es la globalización? Falacias del globalismo, respuestas a la globalización. Barcelona: Paidós.

-Beiner, R. (2000). Community versus Citinzenship: MacIntyre's Revolt Againts the Modern State. Critical Review, 14(4), 459-479.

-Christiansen, C. (2010). Metaphysics and Society: A Commentary on Caritas in veritate, world. Theological Studies, 71(1), 3-28.

-Crepaldi, G. (s/f). Awaiting the New Encyclical of Benedict XVI: What does it mean to say the social doctrine of the Church is timely? Recuperado de http://web.archive.org/web/20090712142225/http://www.vanthuanobse rvatory.org/p_en/news.php?id_news $=689$.

-Coleman, J. (1994). MacIntyre and Aquinas. En J. Horton, S. Mendus, (Ed.), After MacIntyre: Critical Perspectives on the Work of Alasdair MacIntyre (pp. 6590). Oxford: Polity Press.

-Fernández-Llebrez, F. (1999). La ambigüedad comunitarista de Alasdair MacIntyre. El problema de las etiquetas en el debate Liberalismo /Comunitarismo. Revista de Estudios Públicos, 104, 213-231.

-Hibbs, T. (2004). MacIntyre, Aquinas and Politics. The Review of Politcs, 66(3), 357-383.

-Jones, G. (1987). Alasdair MacIntyre on Narratibe, Community, and The Moral Life. Modern Theology, 4(1), 64-65.

-Laurent, B. (2010). Caritas in veritate as a Social Encyclical: a Modest Challenge to Economic, Social, and Political Institution. Theological Studies, 71(3), 515544.

-MacIntyre, A. (1984). Tras la virtud. (A. Valcárcel, Trad.). Barcelona: Editorial Crítica.

-MacIntyre, A. (1990). Three Rival Versions of Moral Enquiry: Encyclopaedia, Genealogy, and Tradition. Notre Dame: University of Notre Dame Press.

-MacIntyre. A. (1991). I'm not communitarism, but.... The Resposive Community, 1(3), 91-92.

-MacIntyre. A. (1995). The spectre of communitarianism. Radical Philosphy, 70, 34-35.

-MacIntyre, A. (1999a). Politics, Philosophy and the Common God. En K. Knight (Ed.), The MacIntyre Reader (pp. 235-252). Notre Dame: University of Notre Dame Press.

-MacIntyre, A. (1999b). Dependent rational Animals: Why Human Need the Virtues. Londres: Duckworth. 
-MacIntyre, A. (2006). Natural law as subversive: the case of Aquinas. En Ethics and Politics: selected essays (Vol. 2, pp. 41-63). Cambridge: Cambridge University Press.

-McMylor, P. (1994). Alasdair MacIntyre: Critic of Modernity. Londres: Routledge.

-Nicholas, J. (2011). Local Communities and Globalization in Caritas in veritate. Solidarity: The Journal of Catyholic Social Thought and Secular Ethics, 1(1), 1115.

-Pérez Andreo, B. (2010). Caritas in veritate: la "kehre" de la Doctrina Social. Veritas, 22, 33-51.

-Pinkard, T. (2003). MacIntyre's Critique of Modernity. En M. Murphy (Ed.), Alasdair MacIntyre (pp. 176-200), Cambridge: Cambridge University Press.

-Robertson, R. (2000). Glocalización: tiempo-espacio y homogeneidadheterogeneidad. Zona Abierta, 92-93, 213-242.

-Raztinger, J. (2014). Procedencia y sentido de la doctrina de san Agustín sobre la Civitas. En Obras Completas (Vol. I, pp. 359-378). Madrid: BAC.

-Ruszala, M. (2010). The Methaphysics of Caritas in veritate: Augustinian Theology and Social Thought as a Interpretive Key. The Catholic Social Science Review, 16, 135-148.

-Sowle, L. (2010). Caritas in veritate: Benedicts's Global Reorientation. Theological Studies, 71(2), 291-319.

Sumario: Introducción; 1. Benedicto XVI y la globalización en sus múltiples dimensiones; 2. Las pequeñas comunidades locales en MacIntyre; 3. Posible encuentro entre Benedicto XVI y MacIntyre; Referencias. 